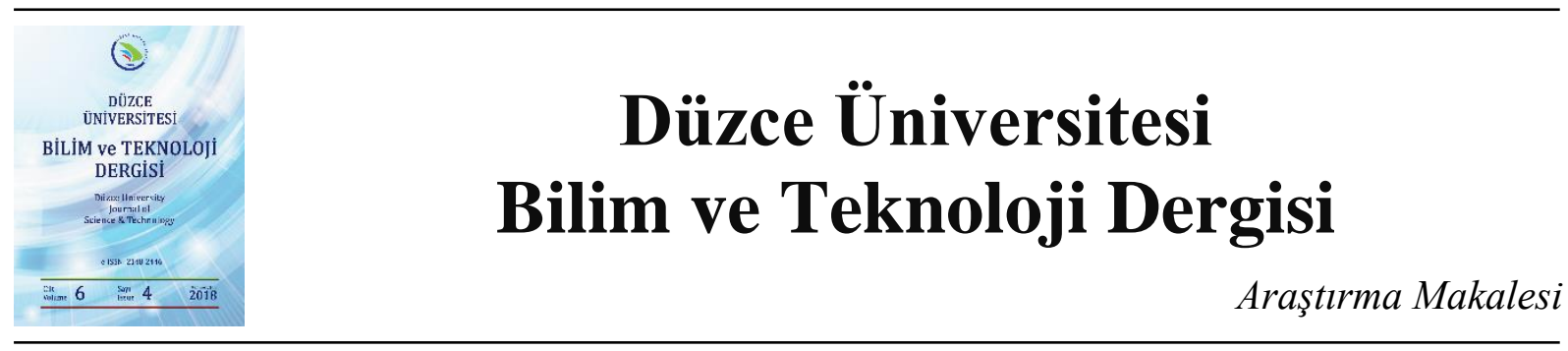

\section{Anzibel Pastillerde Enoksolon-Benzokain-Klorheksidin HPLC Miktar Tayini}

\author{
CumhurÖKÇELIK ${ }^{\mathrm{a}}$, Ece ERGUN ${ }^{\mathrm{b}}$, Ümit ERGUN ${ }^{\mathrm{c}, *}$ \\ ${ }^{a}$ Nobel İlaç Ar-Ge Merkezi, Düzce, TÜRKIYE \\ ${ }^{b}$ Türkiye Atom Enerjisi Kurumu, Sarayköy Nükleer Araşttrma ve Eğitim Merkezi, Ankara, TÜRKIYE \\ ${ }^{c}$ Kimya Bölümü, Fen-Edebiyat Fakültesi, Düzce Üniversitesi, Düzce, TÜRKIYE \\ * Sorumlu yazarin e-posta adresi: umitergun@duzce.edu.tr
}

\begin{abstract}
ÖZET
$\mathrm{Bu}$ çalışmada, antiseptik etkili klorheksidini, antienflamatuar etkili enoksolonu ve lokal anestezik etkili benzokaini bir arada içeren ve bu içeriğiyle ağız-boğaz bölgesindeki lokal irritasyonlara bağlı rahatsızlıkları ortadan kaldırmaya yardımcı olarak kullanılan Anzibel pastillerin maliyet, iş yükü ve zaman açısından daha ekonomik olması nedeniyle miktar tayini analizinin tek bir HPLC yöntemi geliştirilerek, gerekli validasyon çalışmaları tamamlanmıştır. Analizlerde $25^{\circ} \mathrm{CC}^{\prime} \mathrm{de}$ ACE $5 \mathrm{C} 184,6$ x $150 \mathrm{~mm}, 5 \mathrm{~mm}$ kolon, $250 \mathrm{~nm}$ 'de dalga boyunda $0,01 \mathrm{M} \mathrm{KH}_{2} \mathrm{PO}_{4}$ 'In fosforik asit ile $\mathrm{pH} 3,0 \pm 0,05$ 'e ayarlanmış tampon çözeltisi ve asetonitril kullanılmıştır. Sistem uygunluk, doğruluk ve doğrusallık parametreleri çalışılmış ve kabul edilebilir sonuçlar elde edilmiştir.
\end{abstract}

Anahtar Kelimeler: Klorheksidin, enoksolon, benzokain, HPLC

\section{Quantitative HPLC Analysis of Enoxolone-Benzocaine-Chlorhexidine in Anzibel Pastilles}

\begin{abstract}
In this study, Anzibel pastilles are used in the treatment of the diseases related to the local irritation in oropharyngeal area with the antiseptic effect of a chlorhexidine, antiinflammatory effect of an enoxolone and locally anesthetizing effect of benzocaine. Because of economic reasons such as cost, workload and time, a new simultaneous HPLC method has been developed for the quantitative analysis of anzibel pastilles and the validation studies have been completed. Analysis were performed at $25^{\circ} \mathrm{C}$ by using ACE $5 \mathrm{C} 184.6 \mathrm{x} 150 \mathrm{~mm}, 5$ $\mathrm{mm}$ column, mobile phase consisted of a mixture of $0.01 \mathrm{M} \mathrm{KH}_{2} \mathrm{PO} 4 / \mathrm{H}_{3} \mathrm{PO}_{4}$ buffer $(\mathrm{pH}=3.0 \pm 0.05)$ and acetonitrile and PDA dedector set at $250 \mathrm{~nm}$. System suitability,accuracy and linearity parameters were studied and acceptable results were obtained.
\end{abstract}

Keywords: Chlorhexidine, Benzocaine, Enoxolone, HPLC 


\section{GiRISS}

$\mathrm{K}^{\mathrm{s}}$ lorheksidin, bakteri hücre membranının stabilizasyonunu bozar ve membrandan penetre olur. Bakteri hücre sitoplazmasının presipite olmasına yol açar. Hücrenin oksijen kullanımını engelleyerek hücrede ATP düzeylerini düşürür ve sonuçta hücre membranının işlevini bozar. $\mathrm{Bu}$ bakterilerin iç membranları yırtılmaz, fakat küçük molekülleri uptake etme yeteneği zayıflar. Klorheksidin düşük konsantrasyonda bakteriostatik, yüksek konsantrasyonda ise bakterisid etki gösterir.

Benzokain kısa etki süreli, para-aminobenzoik asid (PABA) türevi, ester tipte bir lokal anesteziktir. Beyaz renkli kristal yapılı toz veya renksiz kristaller halinde bulunur. Sinir hücresi zarını geri dönüşümlü olarak stabilize ederek sodyum iyonlarına yönelik geçirgenliğini azaltır. Böylece sinir hücresi zarının depolarizasyonu inhibe olur; bu da sinir uyaranlarının başlatılmasını ve iletilmesini geçici olarak bloke eder. Benzokain suda çok az çözünür, eter ve alkolde ise çok çözünür.

Enoksolon glisiretinik asit beta-amirin tipi pentasiklik bir triterpenoit türevidir. Beyaz veya beyazıms1 kristal tozdur. Enoksolon ekspektoran ve antitussif aktivite gösterir. Klorhekzidin[1-5], benzokain [1, $6,7,8,9]$ ve enoksolonun [10,11] her birinin tek tek analizi ve validasyonlan ile ilgili litaratürde oldukça çok çalışma vardır. Bu çalışmada, antiseptik etkili klorheksidini, antienflamatuar etkili enoksolonu ve lokal anestezik etkili benzokaini bir arada içeren ve bu içeriğiyle ağız-boğaz bölgesindeki lokal irritasyonlara bağlı rahatsızlıkları ortadan kaldırmaya yardımcı olarak kullanılan Anzibel pastillerin maliyet, iş yükü ve zaman açısından daha ekonomik olması nedeniyle tek bir yöntemde miktar tayini analizi yapılmıştır. Litaratürlerde 3 etken maddenin bir arada miktarlandırılmasını sağlayacak bir çalışma yoktur. Yapılan çalışmalar ve analizler sonucunda üç etken madde içeren anzibel pastillerin tek bir HPLC yöntemi ile miktar tayini analizleri gerçekleştirilerek zamandan, cihazdan, iş gücünden kazanmak amacıyla alternatif bir ürün olarak kullanılması düşünülmektedir. Günümüzde ilaç sektöründe artık birbiri ile kombine ürünler çalışıldığından yaptığımız çalışmanın farklı projelere de ilham verici olacağını düşünüyoruz.

\section{MALZEME VE YÖNTEM}

\section{A. REAKTIF VE STANDARTLAR}

\begin{tabular}{ccc}
\hline Reaktif & Firma & Seri Numaras \\
\hline Klorhekzidin $\mathrm{HCl}$ & EP & 2.0 \\
\hline Benzokain & EP & 1.0 \\
\hline Enoksolon & EP & 3.0 \\
\hline Asetonitril & JT Baker & 1707501801 \\
\hline Fosforik Asit & Merck & K47261373 550 \\
\hline $\mathrm{KH}_{2} \mathrm{PO}_{4}$ & Merck & AM1089773 707 \\
\hline $18 \alpha$-glycyrrhetinic acid & Sigma-Aldrich & BCBM5743V \\
\hline
\end{tabular}


<smiles>CCOC(=O)c1ccc(N)cc1</smiles>

Benzokain

MA: $165.19 \mathrm{~g} / \mathrm{mol}$

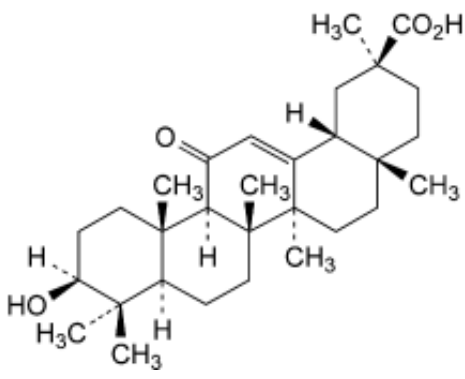

Enoksolon

MA: $470.68 \mathrm{~g} / \mathrm{mol}$<smiles>N=C(NCCCCCCCCCCCCCCCCNC(=N)Nc1ccc(Cl)cc1)NC(=N)Nc1ccc(Cl)cc1</smiles>

Klorheksidin $\mathrm{HCl}$

MA:505.45 g/mol

Şekil 1.Anzibel pastillerde bulunan ü̧ etken maddenin kimyasal yapıları.

\section{B.ANALİTIK YÖNTEM VE ÇÖZELTILLERIN HAZIRLANMASI}

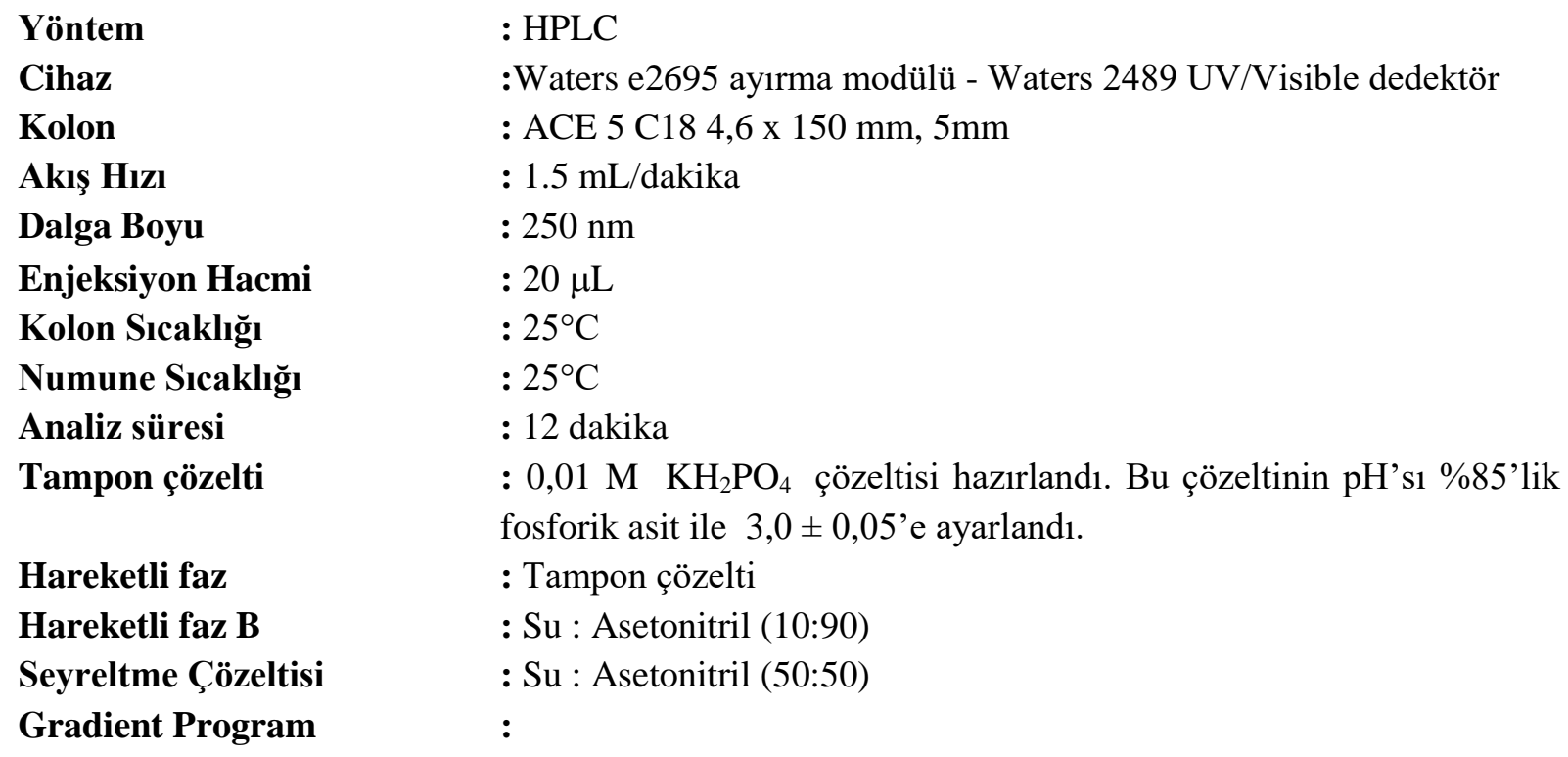

\begin{tabular}{ccc}
\hline Zaman (dakika) & Hareketli Faz A (\%) & Hareketli Faz B (\%) \\
\hline 0 & 70 & 30 \\
\hline 3 & 15 & 85 \\
\hline 8 & 15 & 85 \\
\hline 9 & 70 & 30 \\
\hline 12 & 70 & 30 \\
\hline
\end{tabular}

Standart Çözeltisi: $100 \mathrm{~mL}$ 'lik balon jojeye $50 \mathrm{mg}$ klorhekzidin $\mathrm{HCl}, 40 \mathrm{mg}$ benzokain ve $30 \mathrm{mg}$ enoksolon standardı tartıldı. Bir miktar seyreltme çözeltisi eklenip ultrasonik banyoda 10 dakika bekletildi. Tamamen çözündükten sonra seyreltme çözeltisi ile hacmi $100 \mathrm{~mL}$ 'ye tamamlandı. $\mathrm{Bu}$ çözeltiden $50 \mathrm{~mL}$ 'lik balon jojeye 5,0 mL alındı ve hacmine seyreltme çözeltisi ile tamamlandı. $\mathrm{Bu}$ çözelti 2-3 mL ile doyurulmuş $0,45 \mathrm{~mm}$ PTFE filtreden süzüldü ve viallendi. $\left(\mathrm{C}_{\text {Klorhekzidin } \mathrm{HCl}}=50 \mu \mathrm{g} / \mathrm{mL}\right.$ $\mathrm{C}_{\text {Benzokain }}=40 \mu \mathrm{g} / \mathrm{mL} \mathrm{C}_{\text {Enoksolon }}=30 \mu \mathrm{g} / \mathrm{mL}$ ) 
Test Çözeltisi : 20 adet pastil tartıldı ve ortalama pastil ağırlığı belirlendi. 5 adet pastile eşdeğer pastil tozu $500 \mathrm{~mL}$ 'lik balon jojeye tartıldı. $200 \mathrm{~mL}$ seyreltme çözeltisi ilave edilip ultrasonik banyoda 15 dakika bekletildi. Tamamen çözündükten sonra hacmine seyreltme çözeltisi ile tamamlandı. Bu çözelti 2-3 mL ile doyurulmuş $0,45 \mathrm{~mm}$ PTFE filtreden süzüldü ve viallendi. $\left(C_{\text {Klorhekzidin } \mathrm{HCl}}=50 \mu \mathrm{g} / \mathrm{mL}\right.$ $\mathrm{C}_{\text {Benzokain }}=40 \mu \mathrm{g} / \mathrm{mL} \mathrm{C}_{\text {Enoksolon }}=30 \mu \mathrm{g} / \mathrm{mL}$ )

\section{BULGULAR VE TARTISMA}

\section{A. SISTEM UYGUNLUK ŞARTLARI}

Sistem uygunluğu standart çözeltinin 6 ardışık enjeksiyonu ile kontrol edilir (Şekil 2).Alıkonma zamanı ve alanların bağıl standart sapması \% 0,85'ten küçük ve simetri faktörü klorhekzidin için 0,8 1,8 arasında, benzokain ve enoksolon için 0,8-1,5 arasında olmalıdır. Teorik plaka sayları 5000'den büyük olmalı ve klorhekzidin ile benzokain arasındaki ayrışma 5 'ten büyük olmalıdır.

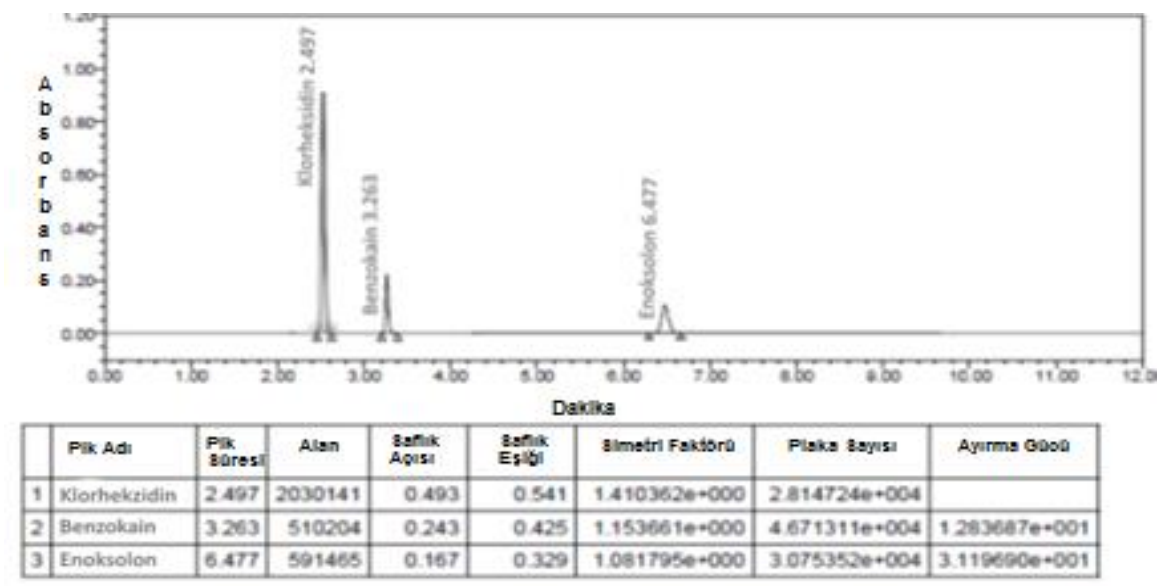

Şekil 2.Sistem uygunluk çözeltisi kromatogramı.

\section{B. DOĞRULUK}

Kullandığımız çözücü ve konsantrasyonda ürünün içerisinden klorhekzidin, enoksolon ve benzokaini tam olarak çözeltiye alıp alamadığımızın kontrolü için doğruluk çalışması yapılmıştır. Üretim sırasında oluşacak hatalar kaynaklı miktar tayini sonucundaki sapma ve varyasyonları tespit edebilmek adına bu çalışma \%80 ‘den \%120’ye kadar geri kazanım aralıklarında yapılmıştır.

Tablo 1.Klorhekzidin Geri Kazanım Sonuçları.

\begin{tabular}{cccc}
\hline Klorhekzidin HCl & $\begin{array}{c}\text { Hazırlanan } \\
\text { Konsantrasyon } \\
(\boldsymbol{\mu g} / \mathbf{m L})\end{array}$ & $\begin{array}{c}\text { Bulunan } \\
\text { Konsantrasyon } \\
(\boldsymbol{\mu g} / \mathbf{m L})\end{array}$ & $\begin{array}{c}\text { Geri Kazanım } \\
\%\end{array}$ \\
\hline$\% 80$ & 40,3 & 39,8 & 98,76 \\
\cline { 2 - 4 } & 40,7 & 40,0 & 98,28 \\
\hline
\end{tabular}




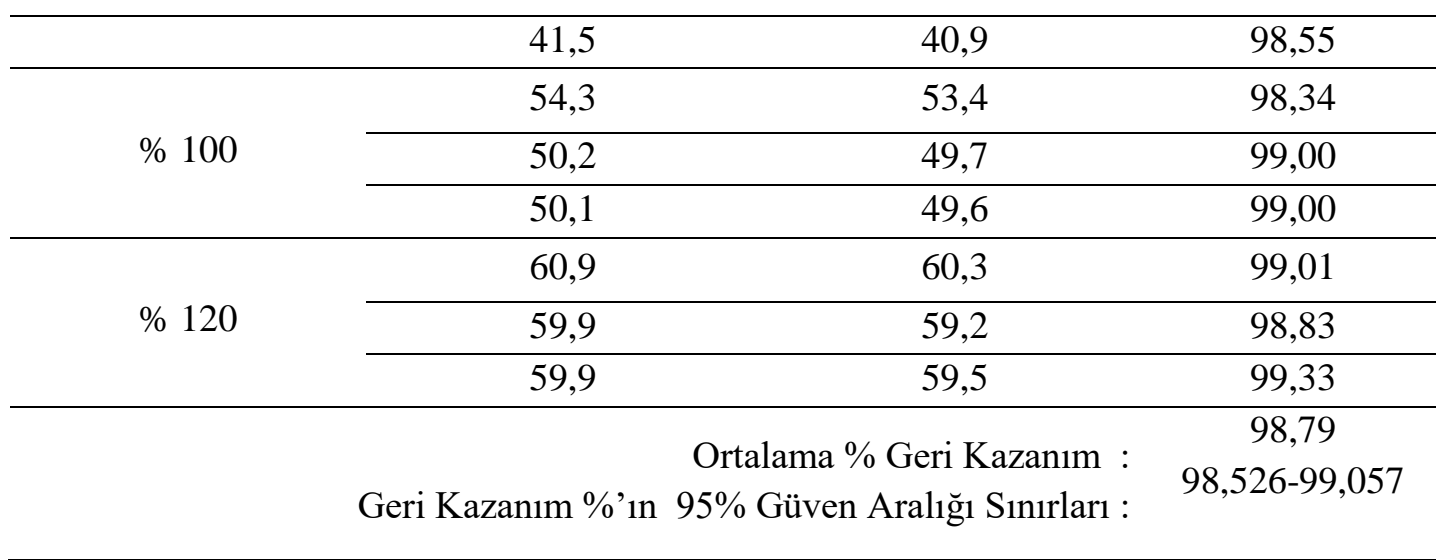

Tablo 2.Benzokain Geri Kazanım Sonuçları.

\begin{tabular}{|c|c|c|c|}
\hline Benzokain & $\begin{array}{c}\text { Hazırlanan } \\
\text { Konsantrasyon } \\
(\mu \mathrm{g} / \mathrm{mL})\end{array}$ & $\begin{array}{c}\text { Bulunan } \\
\text { Konsantrasyon } \\
(\mu \mathrm{g} / \mathrm{mL})\end{array}$ & $\begin{array}{c}\text { Geri Kazanım } \\
\%\end{array}$ \\
\hline \multirow{3}{*}{$\% 80$} & 33,4 & 33,3 & 99,70 \\
\hline & 32,2 & 32,1 & 99,69 \\
\hline & 32,4 & 32,2 & 99,38 \\
\hline \multirow{3}{*}{$\% 100$} & 39,7 & 39,6 & 99,75 \\
\hline & 40,1 & 39,8 & 99,25 \\
\hline & 40,3 & 40,2 & 99,75 \\
\hline \multirow{5}{*}{$\% 120$} & 48,3 & 48,2 & 99,79 \\
\hline & 48,1 & 48,2 & 100,21 \\
\hline & 48,1 & 48,2 & 100,21 \\
\hline & \multicolumn{2}{|c|}{ Ortalama \% Geri Kazanım : } & 99,75 \\
\hline & Kazanım \%'ın 95 & en Aralığı Sınırları : & $99,504-99,993$ \\
\hline
\end{tabular}

Tablo 1, tablo 2 ve tablo 3 'te konsantrasyonlara karş1 geri kazanım sonuçları görülmektedir. Ortalama geri kazanım değeri klorheksidin $\mathrm{HCl}$ için \%98,79;benzokain için \%99,75 ve enoksolon için \%100,08'dir. Bu değerler kabul edilen sınırlar (\%98-\%102) içinde olduğu için Anzibel Pastil Miktar Tayini yöntemi doğruluk parametresine göre uygundur. Şekil 3'te klorhekzidin, enoksolon ve benzokain \%100’lük geri kazanım kromatogramı görülmektedir.

Tablo 3.Enoksolon Geri Kazanım Sonuçları

\begin{tabular}{cccc}
\hline Enoksolon & $\begin{array}{c}\text { Hazırlanan } \\
\text { konsantrasyon } \\
(\boldsymbol{\mu g} / \mathbf{m L})\end{array}$ & $\begin{array}{c}\text { Bulunan } \\
\text { konsantrasyon } \\
(\boldsymbol{\mu g} / \mathbf{m L})\end{array}$ & $\begin{array}{c}\text { Geri Kazanım } \\
\text { \% }\end{array}$ \\
\hline \multirow{2}{*}{$\% 80$} & 23,8 & 23,9 & 100,42 \\
\cline { 2 - 4 } & 23,8 & 23,6 & 99,16 \\
\hline
\end{tabular}




\begin{tabular}{cccc}
\hline & 23,8 & 24,0 & 100,84 \\
\hline \multirow{2}{*}{$\% 100$} & 30,6 & 30,4 & 99,35 \\
\cline { 2 - 4 } & 30,2 & 30,1 & 99,67 \\
\cline { 2 - 4 } & 30,5 & 30,8 & 100,98 \\
\hline \multirow{3}{*}{$\% 120$} & 36,2 & 36,1 & 99,72 \\
\cline { 2 - 4 } & 37,2 & 37,3 & 100,27 \\
\hline \multirow{2}{*}{ Geri Kazanım \%'1n } & \multicolumn{2}{c}{ O5\% Güven Aralığı Sinırları : } & 100,27 \\
\hline
\end{tabular}

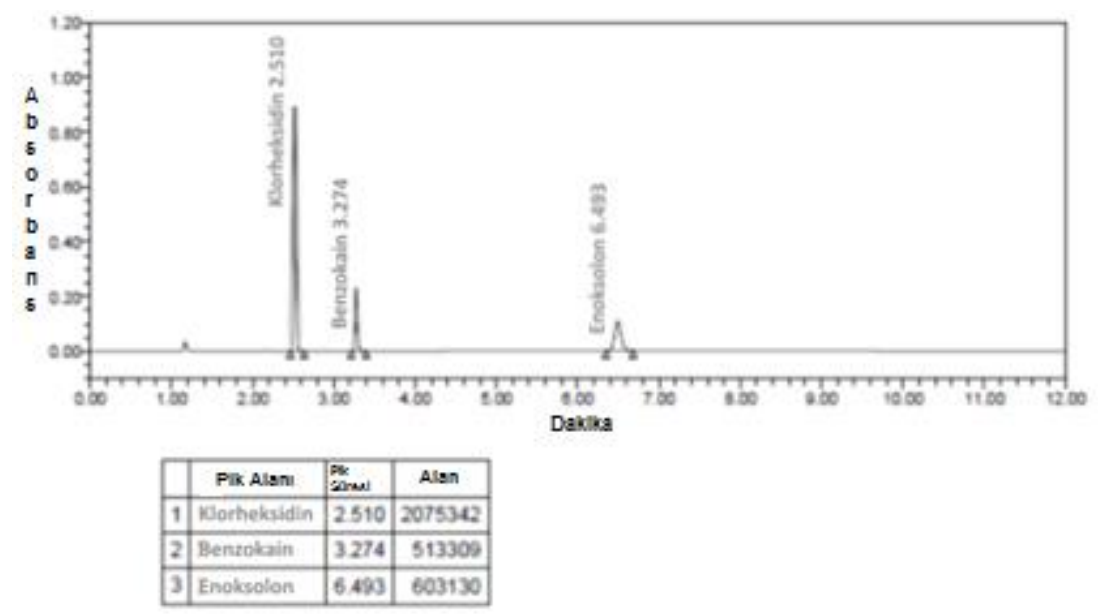

Şekil 3.Doğruluk Kromatogramı \%100( $\left.C_{\text {Klorhekzidin } H C l}=50 \mu \mathrm{g} / \mathrm{mL} ; C_{\text {Benzokain }}=40 \mu \mathrm{g} / \mathrm{mL} ; C_{\text {Enoksolon }}=30 \mu \mathrm{g} / \mathrm{mL}\right)$

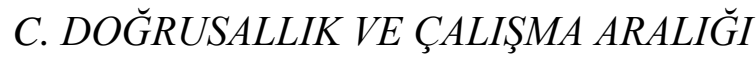

Doğrusallık çalışması bir konsantrasyon aralığındaki numune çözeltilerindeki analit cevabının konsantrasyonla doğru orantılı olduğunun gösterilmesidir.Çalışmaya karar verdiğimiz konsantrasyonun doğrusallık çalışma aralığ 1 içerisinde olup olmadığını kontrol etmek ve lineerlik eğrisinden elde edilen kesişim değeri \%100 standart için elde edilen alanın \%2'sinden büyük olmadığını kanıtlamak için standart konsantrasyonu \%100 kabul edilerek \%50 ile \%150 arasında 6 farklı konsantrasyonda standart çözeltiler hazırlandı ve dogrusallık grafikleri çizildi.Tablo 4 , tablo 5 ve tablo 6'da konsantrasyonlara karşı bulunan ve lineerlik denkleminden hesaplanan sonuçlar görülmektedir.Şekil 4, şekil 5 veşekil 6' da klorhekzidin, enoksolon ve benzokain doğrusallık grafikleri görülmektedir.y-kesişimi, \% 100 seviyesindeki analit için elde edilen; klorheksidin alanının \% 1,60'1, benzokain alanının \%0,25'i ve enoksolon alanının \%0,28'idir. Bu değerler \%2'den küçük olduğu için kabul edilebilirdir. $\mathbf{R}^{2}$ değerleri sınırlar $(>0,995)$ içerisinde olup yöntem doğrusallık parametresine göre uygundur.Şekil 7'de \%100'lük doğrusallık kromatogramı görülmektedir. 
Tablo 4. Klorhekzidin HCl konsantrasyona bağlı kromatogram değerleri.

\begin{tabular}{cccc}
\hline Çözelti Seviyesi & $\begin{array}{c}\text { Klorhekzidin HCl } \\
\text { Konsantrasyonu } \\
(\boldsymbol{\mu g} / \mathbf{m L})\end{array}$ & $\begin{array}{c}\text { Enjeksiyonların } \\
\text { Alan Ortalaması }\end{array}$ & Hesaplanan Alan \\
\hline \% 50 & 24,8 & 1008428 & 1010330 \\
\hline $\mathbf{\% ~ 6 0}$ & 29,7 & 1216714 & 1239588 \\
\hline $\mathbf{\% ~ 8 0}$ & 39,6 & 1633286 & 1661161 \\
\hline $\mathbf{\% ~ 1 0 0}$ & 49,5 & 2049858 & 2065301 \\
\hline $\mathbf{\% ~ 1 2 0}$ & 59,4 & 2466429 & 2498812 \\
\hline $\mathbf{\% ~ 1 5 0}$ & 74,3 & 3091287 & 3126114 \\
\hline
\end{tabular}

Ĕ̆im : 42552348,8718

Kesişim : $-33000,9486$

$\mathbf{R}: 0,9999$

$\mathbf{R}^{2}$ : 0,9999

$\mathbf{y}=\mathbf{m x}+\mathbf{n}: \quad \mathrm{y}=42552348,8718 \mathrm{x}-33000,9486$

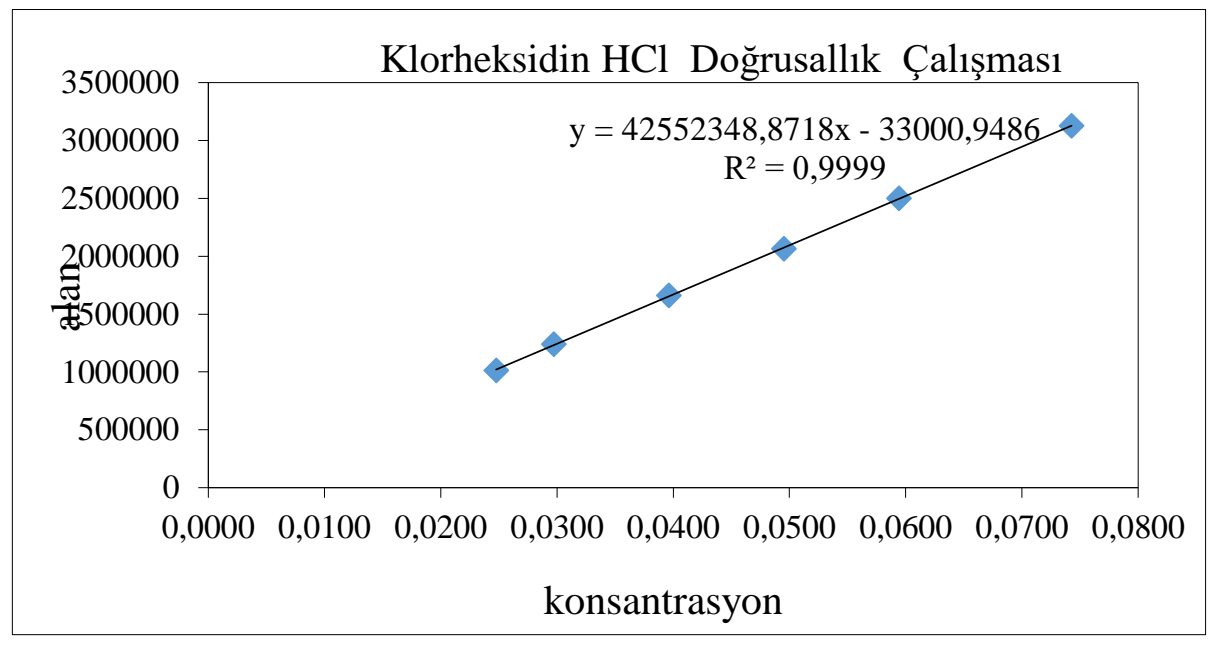

Şekil 4.Klorhekzidin HCl doğrusallık grafiği.

Tablo 5.Benzokain konsantrasyona bağlı kromatogram değerleri.

\begin{tabular}{cccc}
\hline Çözelti Seviyesi & $\begin{array}{c}\text { Benzokain } \\
\text { Konsantrasyonu } \\
(\boldsymbol{\mu g} / \mathbf{m L})\end{array}$ & $\begin{array}{c}\text { 3 Enjeksiyonun } \\
\text { Alan Ortalaması }\end{array}$ & Hesaplanan Alan \\
\hline \% 50 & 19,7 & $\mathbf{2 6 0 6 9 6}$ & $\mathbf{2 5 9 4 3 2}$ \\
\hline$\%$ 60 & 23,7 & $\mathbf{3 0 9 5 9 0}$ & $\mathbf{3 1 1 0 6 5}$ \\
\hline \% 80 & 31,6 & $\mathbf{4 1 5 3 3 3}$ & $\mathbf{4 1 4 3 3 1}$ \\
\hline$\% \mathbf{1 0 0}$ & 39,5 & $\mathbf{5 1 6 3 8 7}$ & $\mathbf{5 1 7 5 9 8}$ \\
\hline$\% \mathbf{1 2 0}$ & 47,4 & $\mathbf{6 2 0 7 5 8}$ & $\mathbf{6 2 0 8 6 4}$ \\
\hline
\end{tabular}




\begin{tabular}{rlr}
\hline \% 150 & \multicolumn{1}{c}{$\mathbf{7 7 6 2 9 1}$} & $\mathbf{7 7 5 7 6 4}$ \\
\hline Eŭim : & 13082896,7756 \\
Kesişim : & 1265,5911 \\
$\mathbf{R}:$ & 0,9999 \\
$\mathbf{R}^{2}:$ & 1,000 \\
$\mathbf{y =} \mathbf{m x}+\mathbf{n}:$ & $\mathbf{y}=13082896,7756 x+1265,5911$ \\
\hline
\end{tabular}

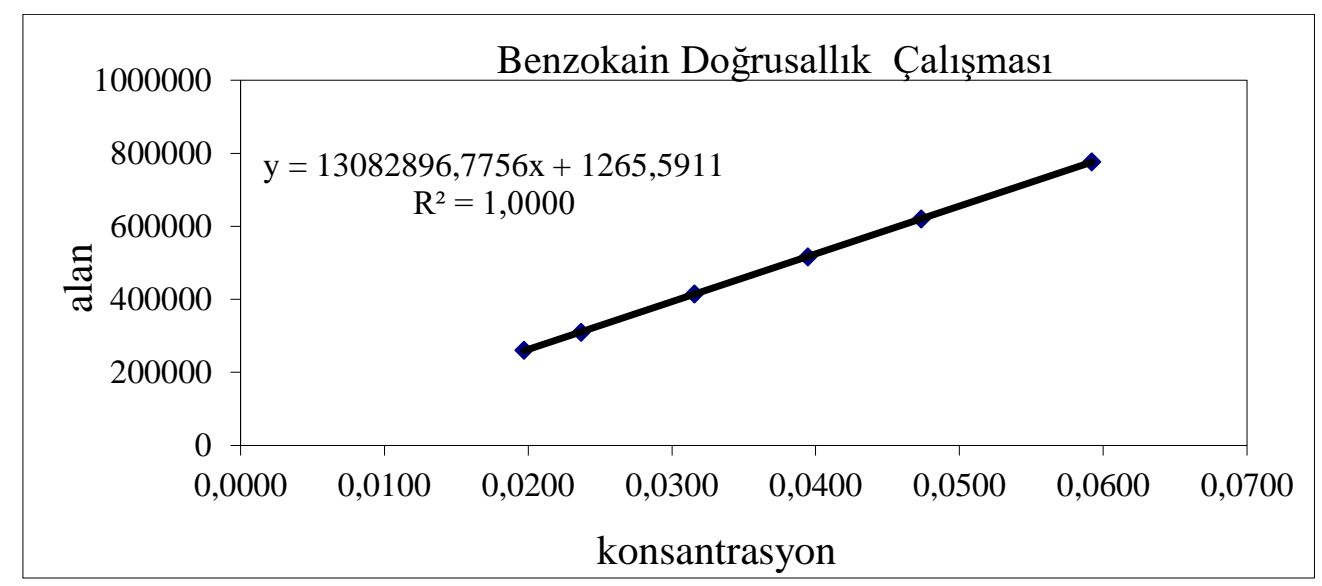

Şekil 5. Benzokain doğrusallık grafiği.

Tablo 6. Enoksolon konsantrasyona bağlı kromatogram değerleri.

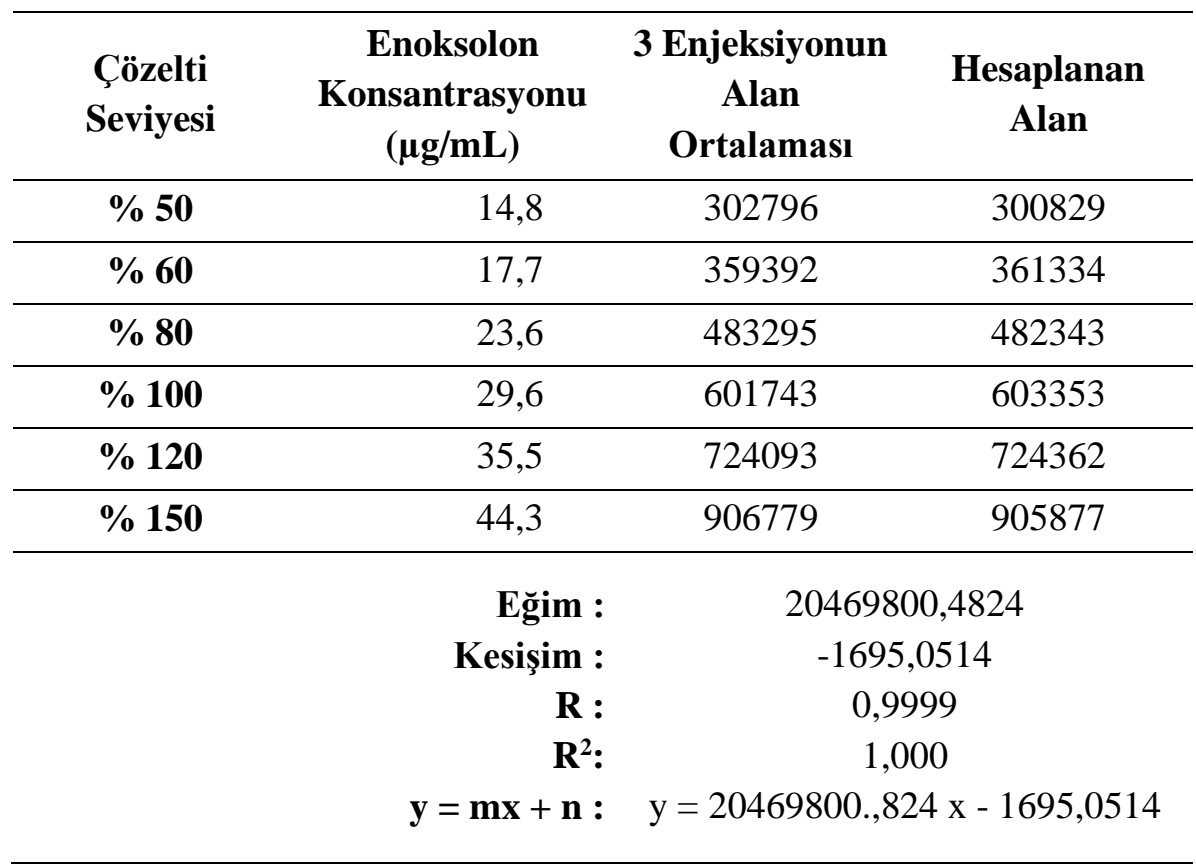




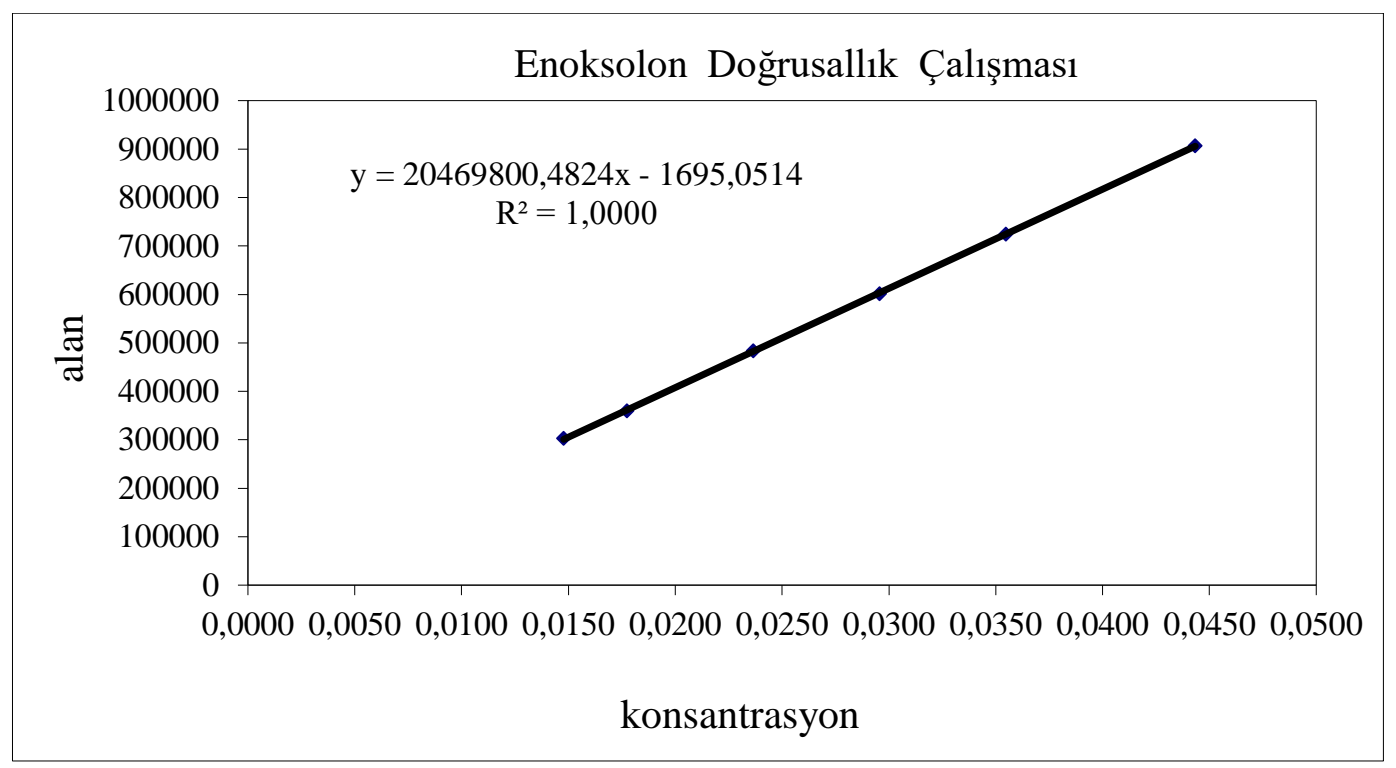

Şekil 6.Enoksolon doğrusallık grafiği.

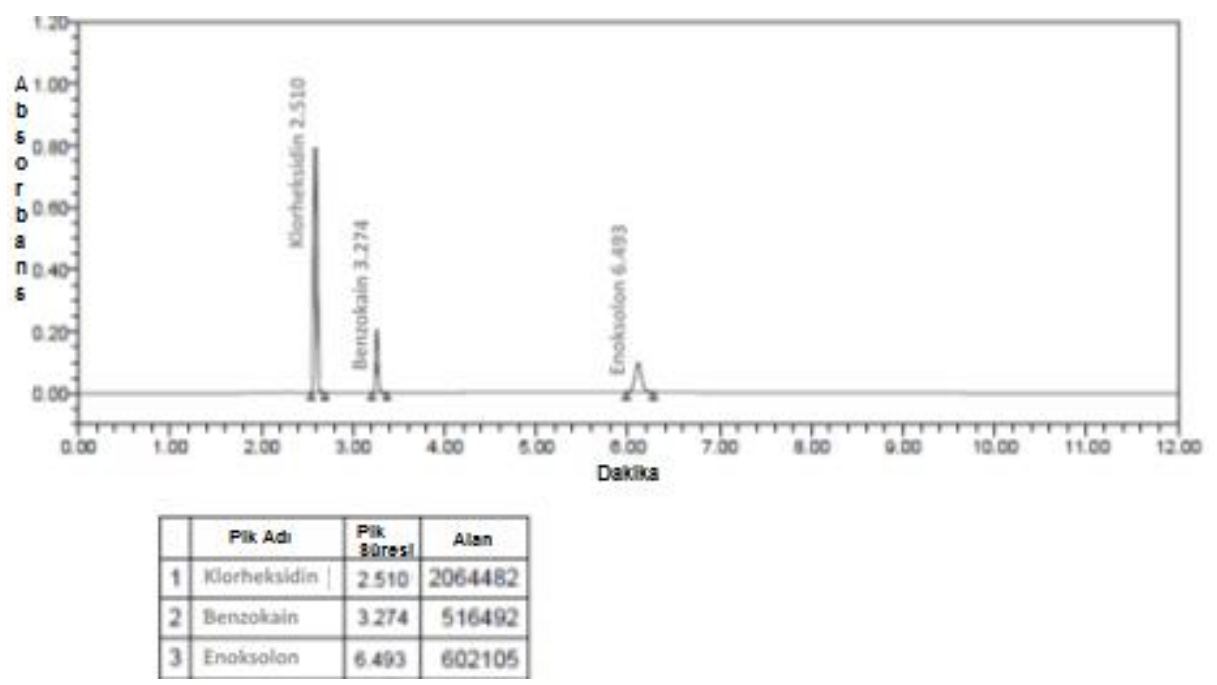

Şekil 7. Doğrusallık kromatogramı ( $C_{\text {Klorhekzidin } H C l}=50 \mu \mathrm{g} / \mathrm{mL} ; C_{\text {Benzokain }}=40 \mu \mathrm{g} / \mathrm{mL} ; \quad C_{\text {Enoksolon }}=30 \mu \mathrm{g} / \mathrm{mL}$ ).

\section{SONUC}

Yapılan çalışmalar sonucu, 12 dakikalık enjeksiyon süresinde 3 etken maddeninde çıkartıldığı bir HPLC yöntemi yapılmış ve valide edilebilmiştir. Etken maddelerin alıkonma zamanları, klorhekzidin için yaklaşık 2,5 dakika; benzokain için yaklaşık 3,2 dakika ve enoksolon için ise yaklaşık 6,5 dakika olarak ayarlanmıştır. Sistem uygunluk şartlarının tespiti için şekil 2'den aşagıdaki sonuçlar elde edilmiştir ve buna göre sistemimiz sistem uygunluk parametlerini sağlamaktadır.

- Alıkonma zamanı ve alanların Bağıl standart sapması $\% 0,85$ ’ten küçük bulunmuştur

- Simetri faktörü Klorhekzidin için 0,8-1,8 arasında, benzokain ve enoksolon için 0,8-1,5 arasında bulunmuştur.

- Teorik plaka sayları 5000'den büyük bulunmuştur. 
- Klorhekzidin ile Benzokain'in arasındaki ayrışma 5'ten büyüktür.

Doğruluk parametresinin belirlenmesinde klorheksidin $\mathrm{HCl}$ için \%98,79; benzokain için \%99,75 ve enoksolon için \%100,08 geri kazanım değerleri elde edilmiştir. Bu sonuçlar kabul kriteri olan \%98\%102 aralığı içerisinde olduğundan yöntemimiz doğruluk parametresi açısından uygundur.Doğrusallık parametresi için elde edilen değerler her 3 etken madde için elde edilen y-kesişim değerleri \%2'den küçük olduğundan yöntemimiz doğrusallık parametresine göre de uygundur.Elde edilen korelasyon katsayısı ve $\mathrm{R}^{2}$ değerleri de bunu desteklemektedir.

TEȘEKKÜR: Proje Nobel ilaç AR-GE merkezi tarafından desteklenmiştir.

\section{KAYNAKLAR}

[1] 1RxMediaPharma 2017, İnteraktif İlaç Bilgi Kaynağ1

[2] T. Personen, J. Holmalahti and J. Pohjola, "Determination of chlorhexidine in saliva using high-performance liquid chromatography," Journal of Chromatography \& BiomedicalApplications, c. 665, ss. 222-225, 1995.

[3] L.Havlíková, L. Matysová, L. Nováková, R. Hájková and P. Solich, "HPLC determination of chlorhexidine gluconate and p-chloroaniline in topical ointment," Journal of Pharmaceutical and Biomedical Analysis, c. 43, ss. 1169-1173, 2007.

[4] Y. Ha and A. P. Cheung, "New stability-indicating high performance liquid chromatography assay and proposed hydrolytic pathways of chlorhexidine,"JournalofPharmaceuticaland Biomedical Analysis, c. 14, ss. 1327-1334, 1996.

[5] F. Fiorentino, M. Corrêa, H. Regina and N. Salgado, "Analytical Methods for the Determination of Chlorhexidine: A Review," Critical Reviews in Analytical Chemistry, c. 40, s. 2, ss. 89-101, 2010.

[6] L.R. Paschoal and W.A. Ferreira, "Simultaneous determination of benzocaine and cetylpiridinium chloride in tablets by first-derivative spectrophotometric method," Il Farmaco, c. 55, ss. 687-693, 2000.

[7] P. Perez-Lozano, E. Garcia-Montoya, A. Orriols, M. Minarro, J.R. Tico and J.M. Sune-Negre, "A new validated method for the simultaneous determination of benzocaine, propylparaben and benzyl alcohol in a bioadhesive gel by HPLC," Journal of Pharmaceutical and Biomedical Analysis, c. 39, ss. 920-927, 2005.

[8] H. A. Merey, "Simple spectrophotometric methods for the simultaneous determination of antipyrine and benzocaine," Bulletin of Faculty of Pharmacy, c. 54, ss. 181-189, 2016.

[9] H. A. Merey and H. E. Zaazaa, "Validated simultaneous determination of antipyrine and benzocaine $\mathrm{HCl}$ in the presence of benzocaine $\mathrm{HCl}$ degradation product," Royal Society of Chemistry: Analytical Methods, c. 6, ss. 6044-6050, 2014. 
[10] S. Esmaeili, F. Naghibi, M. Mosaddegh and N. Nader, "Determination of $18 \beta$-Glycyrrhetinic Acid in Glycyrrhiza glabra L. Extract by HPLC," Iranian Journal of PharmaceuticalResearch, c. 2, ss. 137-141, 2006.

[11] V. Andrisano, V. Cavrini, D. Bonazzi, "HPLC Determination of 18 [3-Glycyrrhetinic and Glycyrrhizinic Acids in Toothpastes after Solid Phase Extraction," Chromatographia, c. 35, ss. 167$172,1993$. 